\title{
Unique molecular mechanisms for maintenance and alteration of genetic information in the budding yeast Saccharomyces cerevisiae
}

Sayoko Ito-Harashima* and Takashi Yagi

\begin{abstract}
The high-fidelity transmission of genetic information is crucial for the survival of organisms, the cells of which have the ability to protect DNA against endogenous and environmental agents, including reactive oxygen species (ROS), ionizing radiation, and various chemical compounds. The basis of protection mechanisms has been evolutionarily conserved from yeast to humans; however, each organism often has a specialized mode of regulation that uses different sets of machineries, particularly in lower eukaryotes. The divergence of molecular mechanisms among related organisms has provided insights into the evolution of cellular machineries to a higher architecture. Uncommon characteristics of machineries may also contribute to the development of new applications such as drugs with novel mechanisms of action. In contrast to the cellular properties for maintaining genetic information, living organisms, particularly microbes, inevitably undergo genetic alterations in order to adapt to environmental conditions. The maintenance and alteration of genetic information may be inextricably linked to each other. In this review, we describe recent findings on the unconventional molecular mechanisms of DNA damage response and DNA double-strand break (DSB) repair in the budding yeast Saccharomyces cerevisiae. We also introduce our previous research on genetic and phenotypic instabilities observed in a clonal population of clinically-derived $S$. cerevisiae. The molecular mechanisms of this case were associated with mutations to generate tyrosine-inserting tRNA-Tyr ochre suppressors and the position effects of mutation frequencies among eight tRNA-Tyr loci dispersed in the genome. Phenotypic variations among different strain backgrounds have also been observed by another type of nonsense suppressor, the aberrant form of the translation termination factor. Nonsense suppressors are considered to be responsible for the genome-wide translational readthrough of termination codons, including natural nonsense codons. The nonsense suppressor-mediated acquisition of phenotypic variations may be advantageous for adaptation to environmental conditions and survival during evolution.
\end{abstract}

Keywords: Saccharomyces cerevisiae, DNA damage response, dNTP pool, DNA repair, Non-homologous end joining (NHE)), Homologous recombination (HR), Mutation, Nonsense suppressors, Phenotypic variation, Environmental adaptation

\footnotetext{
* Correspondence: sayo1196hara@riast.osakafu-u.ac.jp

Department of Biological Sciences, Graduate School of Science, Osaka

Prefecture University, 1-2 Gakuen-cho, Naka-ku, Sakai, Osaka 599-8570, Japan
} 


\section{Background}

Yeasts are important microorganisms in human life because they have been used for fermentation to produce beverages and foods, such as beer, wine, sake, and breads. The budding yeast Saccharomyces cerevisiae, the genome project of which was completed in 1996 [1], has also been playing significant roles as a model organism in biological and medical sciences. S. cerevisiae is easy to culture, and many experimental procedures such as gene transfer techniques and biochemical and classical genetic analyses have already been established. The most attractive feature is that the DNA fragments introduced into S. cerevisiae cells are homologously recombined at the region with homology (plasmids or chromosomes) at an extremely high frequency. This characteristic enables genetic manipulations to be performed very easily such as the knockout of chromosomal genes. Yeast is a unicellular organism with a similar cellular structure to higher eukaryotes including humans. The functions and expression patterns of genes are highly conserved from yeast to humans, and many human genes were cloned by the complementation of yeast mutants. For instance, basic regulatory mechanism of cell cycle, which is associated with tumor formation in mammals, has been well established in $S$. cerevisiae [2, 3]. Although these characteristics firmly established $S$. cerevisiae as a model organism, a number of studies have shown the uncommon features of phenomena and molecular mechanisms that are specific to this yeast. The fission yeast Schizosaccharomyces pombe may be a suitable model for understanding the biological nature of higher eukaryotes, particularly humans. S. pombe is evolutionarily and functionally highly divergent from $S$. cerevisiae. A comparative genome study suggested that these two yeasts diverged approximately 300-400 million years ago [4]. In contrast to $S$. pombe, $S$. cerevisiae has simpler centromere structures, and quite different composition of factors for histone methylation and heterochromatin organization. Furthermore, S. cerevisiae lacks RNA interference (RNAi) pathway, and scarcely contains introns in its genes [1,5-7]. However, divergent molecular mechanisms among organisms reveal how cellular machineries acquired a higher architecture during evolution. Furthermore, the unique characteristics of machineries may be applicable to applied biology such as drug discovery with novel mechanisms of action. In contrast to the mechanisms to maintain the fidelity of genetic information, living organisms accept genetic alterations, which may occur via multiple mechanisms, to survive against environmental stress. The maintenance and alteration of genetic information are associated with the capacity of DNA repair, and are inextricably linked to each other.

In the early part of this article, we review the unique molecular mechanisms of DNA damage response and
DNA DSB repair specific to $S$. cerevisiae. We then discuss our previous study on genetic and phenotypic instability in a clonal population of clinically-derived $S$. cerevisiae. We elucidated the molecular mechanisms of this case, which are associated with the formation of tRNA-Tyr ochre suppressors and the strong position effects of mutation frequencies in eight tRNA-Tyr loci dispersed in the genome. The bias of mutation frequencies appeared to be due to differences in the efficiency of mismatch DNA repair and translesion DNA synthesis at different loci. Furthermore, ochre suppressors caused variable phenotypes among cells depending on the mutated locus. Another type of nonsense suppressor, $\mathrm{PSI}^{+}$, a prion form of the translation termination factor in $S$. cerevisiae, also confers phenotypic variations in different strain backgrounds upon environmental stress. Nonsense suppressors that cause the genome-wide translational readthrough of termination codons and phenotypic variations may be advantageous for adapting to environmental conditions and be a driving force for evolution.

\section{Ribonucleotide reductase (RNR) and its regulator: Excellent biomarkers for DNA damage responses}

Upon DNA damage and DNA replication inhibition, eukaryotic cells activate cell cycle checkpoint functions. DNA damage checkpoint pathways are highly conserved between S. cerevisiae and humans [8]. The central components in checkpoint functions are ATM/ATR in humans and their homologs, Tel1p/Mec1p in S. cerevisiae, members of the phosphatidylinositol-3-kinase family [9, 10]. Signals received from the sensors for DNA damage and replication arrest are transduced through Tel1p/Mec1p, leading to the phosphorylation of the downstream transducers Rad53p and Dun1p protein kinases [8]. The activation of the checkpoint kinase cascade causes cell cycle arrest and the transcriptional induction of genes encoding subunits of RNR (RNR2, RNR3, and RNR4) and its regulator Hug1p (Hydroxyurea, Ultraviolet, and Gamma radiation 1) as well as DNA repair genes (Fig. 1) [11]. Figure 2 shows the mechanism of the transcriptional induction of DNA damage response genes mediated by Crt1p, one of the effector proteins that take part in the DNA damage and replication stress checkpoint pathway in S. cerevisiae [12]. Crt1p is a DNA-binding protein that binds to the promoter region of damage-inducible genes, including RNR2-4 and HUG1, and represses their transcription by recruiting the general repressor complex Tup1p-Ssn6p [11]. In response to DNA damage or replication blocking, Crt1p is phosphorylated via the Mec1p-Rad53p-Dun1p kinase cascade and is then released from DNA, leading to the dissociation of the repressor complex and activation of target genes [11, 13]. The expression of RNR2-4 and HUG1 genes is induced by treatments with methyl methanesulfonate (MMS), hydroxyurea (HU), ultraviolet (UV), and $\gamma$ rays [14-17]. In a 


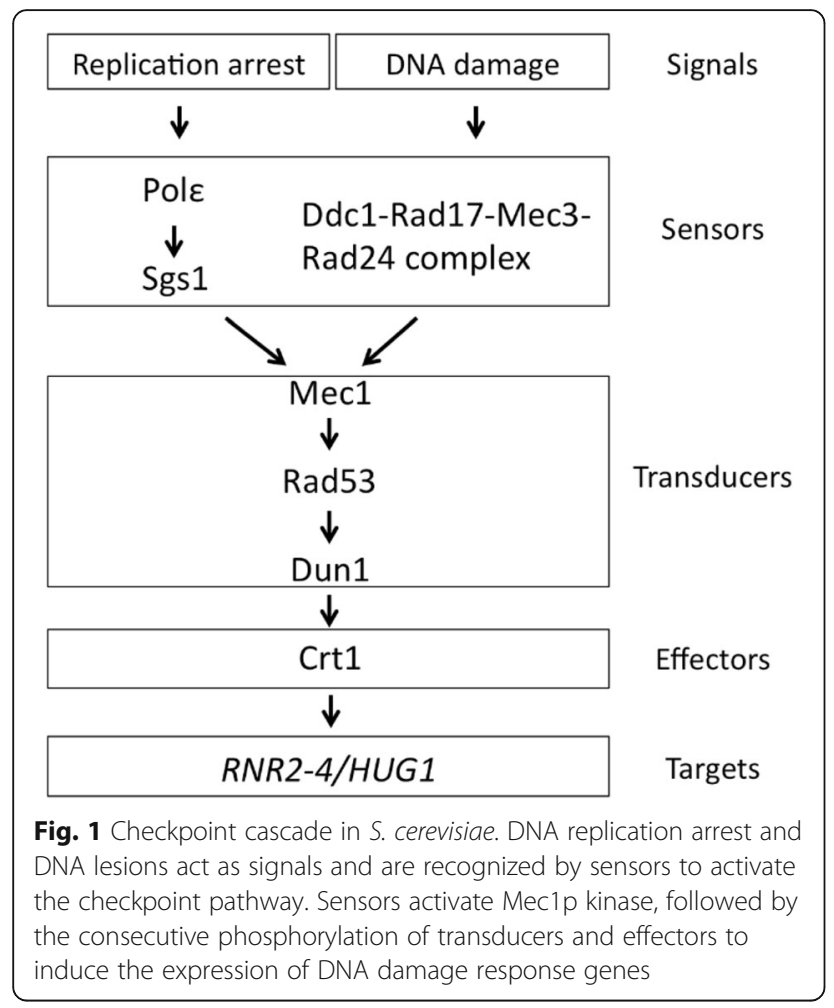

previous study to examine responses to high-linear energy transfer (LET) ionizing radiation (IR), global gene expression in S. cerevisiae cells irradiated by three types of highLET IR (fast neutrons, heavy ions, and thermal neutrons) and $\gamma$ rays was investigated using a DNA microarray analysis. Five genes were induced by all forms of high-LET IR and $\gamma$ rays, all of which are involved in the checkpoint pathway for DNA damage including RNR2, RNR4, and HUG1. The expression levels of these genes were up-regulated by 2.5- to 9-fold [18].

Deoxyribonucleoside triphosphate (dNTP) levels affected by RNR activity were increased more in S. cerevisiae during DNA damage responses than in $S$. pombe and mammalian cells [19-22]. Thus, changes in the expression levels of $R N R$ genes and the HUG1 gene appear to be marked. The induction of these genes upon DNA damage was also shown to be independent of the cell cycle stage, suggesting their properties as excellent biomarkers to detect DNA damage and replication-blocking agents in $S$. cerevisiae.

\section{Control of intracellular dNTP pools in S. cerevisiae: Tight regulatory mechanisms by three small proteins}

RNRs are essential enzymes that catalyze the reduction of ribonucleotides to deoxyribonucleotides, the rate-limiting step in dNTP production, and play an essential role in de novo DNA synthesis [22]. The levels of dNTP pools are primarily regulated by RNR. It is suggested that the increased dNTP pools are required for optimal function of DNA polymerases to repair damaged DNA. Interestingly, the large pool expansions also increased mutation frequency [19].

In most eukaryotes, class Ia RNRs consist of a large R1 subunit ( $\alpha_{2}$ homodimer) and small R2 subunit ( $\beta_{2}$ homodimer). In $S$. cerevisiae, four genes, $R N R 1-4$, encode Rnr proteins: the Rnr1p homodimer forms R1, while the Rnr2p and Rnr4p heterodimer forms R2, which is an exceptional case in eukaryotes (Fig. 3) [23-25]. Rnr3p, a minor isoform of Rnr1p, is induced in response to DNA damage [26]. R1 is constitutively localized in the cytoplasm, whereas R2 is predominantly localized in the nucleus in the non-S-phase of the cell cycle. In response to S-phase entry or the activation of the DNA damage checkpoint, R2 is relocalized to the cytoplasm, where the RNR holoenzyme complex is formed to catalyze dNTP synthesis [27]. The enzymatic activity of RNR may be modulated by the binding of inhibitor proteins and dynamic changes in the subcellular localization of the R2 subunit.

Three small intrinsically disordered proteins lacking fixed or ordered three-dimentional structure: Dif1p, Sml1p, and Hug1p, which are regulated by the checkpoint pathway, are involved in RNR regulation in S. cerevisiae. A synteny analysis suggested that these genes are derived from the same

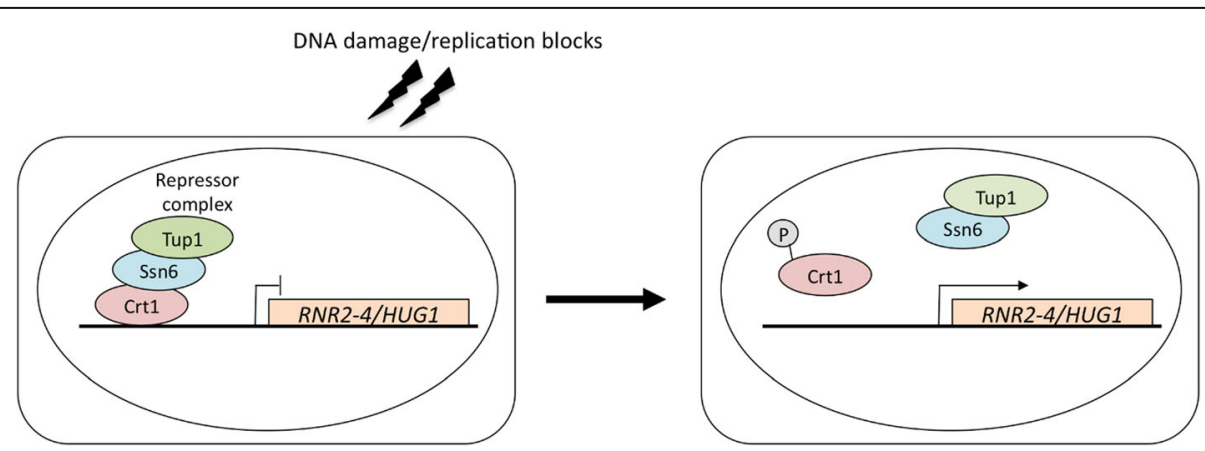

Fig. 2 Regulatory mechanism of expression of DNA damage response genes by the checkpoint pathway. Upon the phosphorylation of Dun $1 p$ by the checkpoint pathway, Crt1p in the repressor complex bound to the promoter region of damage-inducible genes is phosphorylated. This leads to the dissociation of the repressor complex from the promoter to induce the expression of target genes 


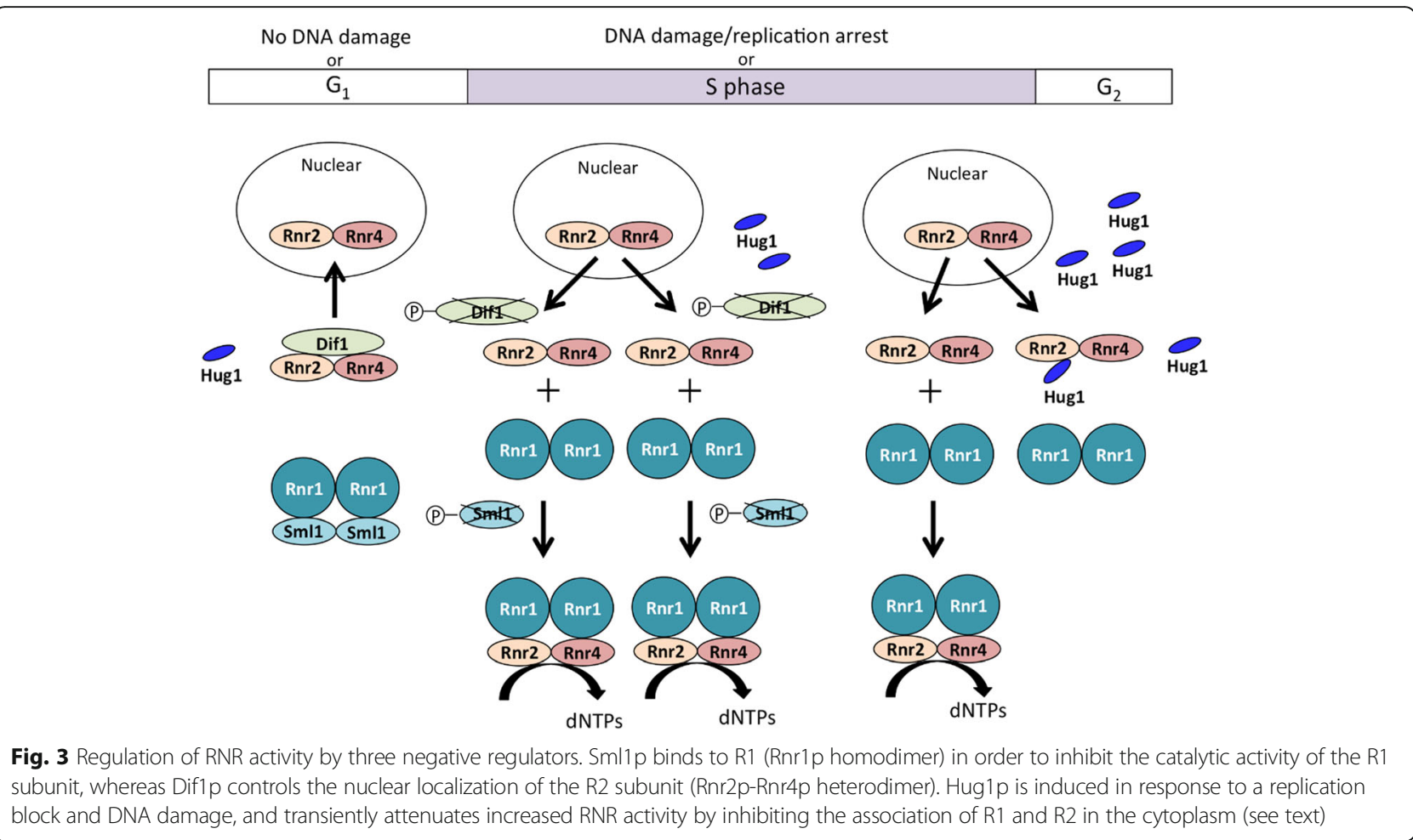

ancestral locus, diverging when S. cerevisiae underwent whole genome duplication during its evolutionary process [28]. The DIF1 region, a putative ancestral gene on chromosome XII was duplicated and its paralog was split into the two separately transcribed genes, HUG1 and SML1, located in tandem on Chromosome XIII (Fig. 4) [29]. These three protein factors are involved in the downregulation of RNR activity, whereas the molecular mechanisms diverged. Dif1p binds directly to the R2 complex to drive nuclear import $[29,30]$. Sml1p directly binds to cytosolic R1 and inhibits its catalytic activity [31-33]. During the S-phase and DNA damage response, Dun1p phosphorylates Dif1p and Sml1p, triggering ubiquitinationmediated degradation [34, 35]. The degradation of Dif1p and Sml1p allows the cytoplasmic localization of R2 and release of R1, respectively, followed by the association of R1 and R2 complexes in the cytoplasm to stimulate dNTP synthesis (Fig. 3). In S. pombe, Spd1 is important for the regulation of RNR. Spd1 binds to R1 and R2, affecting the localization of R2 and inhibition of the catalytic activity of

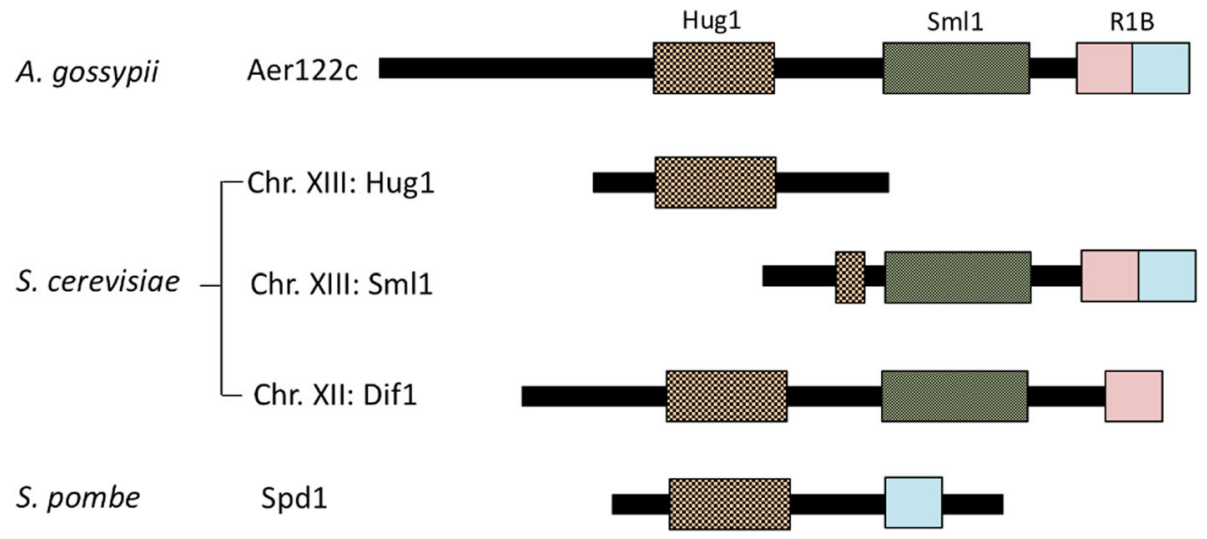

Fig. 4 Structure of RNR regulators. A gossypii Aer122c is considered to be a prototype ancestral protein containing three domains: Hug1 (putative Rnr2p-Rnr4p binding domain), Sml1 (a degron for Smlp degradation after phosphorylation by Dun1p), and R1B (Rnr1p-binding domain consisting of two subdomains, which is inactive in Dif1p). Chromosomal localization of three genes encoding RNR regulators in S. cerevisiae is also depicted in the figure. HUG1 and SML1 genes, located in tandem on chromosome XIII, are transcribed separately 
R1 [36]. Spd1 appears to have the ability to combine Diflp and Sml1p of S. cerevisiae.

Among the three regulatory proteins of S. cerevisiae, the expression of Hug1p only is induced in response to DNA damage and a replication block. Although the role of Hug1p in the checkpoint pathway and DNA damagedependent dNTP synthesis has been suggested, the underlying mechanism remains unknown [13, 37]. Recent studies revealed that Hug1p negatively regulates dNTP synthesis by binding to Rnr2p [38, 39]. The induction of Hug1p in DNA damage responses was slower than Rnr3p, and Hug1p was found to be enriched in the cytoplasm of HU-treated cells [38]. These findings suggest that accumulated Hug1p binds to R2 through interaction with Rnr2p in order to preclude the R1-R2 association in the cytoplasm, leading to the attenuation of RNR activity in post-S-phase or stress conditions. $S$. cerevisiae may concomitantly exploit the allosteric inhibition of RNR and the Huglp-mediated pathway as feedback regulatory mechanisms for the fine-tuning of intracellular dNTP pools in the absence of Sml1p and Diflp. RNR activity is tightly regulated because an imbalanced, excessive, or insufficient supply of dNTPs markedly increases the mutation rate during DNA replication and repair, which may cause genomic instability and cell death [19]. A previous study reported that dNTP synthesis was strongly activated in cancer cells, and the development of anticancer drugs targeting RNR is currently in progress [40]. The regulation of RNR activity by three related proteins is a unique and inventive mechanism to maintain genetic fidelity in S. cerevisiae. This may provide important information for the discovery of novel drugs.

\section{DNA DSB repair in S. cerevisiae}

In eukaryotes, two main repair pathways have been identified for DNA DSBs which are the most detrimental DNA lesions and can be generated by various stresses such as ROS. Homologous recombination (HR) repairs DSBs by retrieving genetic information from an undamaged homolog, whereas nonhomologous end-joining (NHEJ) pathway rejoins them by direct ligation of the strand ends without any requirement for sequence homology [41]. S. cerevisiae mainly uses an HR system of DSB repair, in which exogenous DNA fragments are integrated at homologous sites in the genome if the DNA has a short region of homology at both ends [42]. However, foreign DNA barely integrates into homologous regions on the chromosomes of other organisms. Highly efficient homologous integration is only observed in yeast species of $S$. sensu stricto and Ashbya gossypii, a cotton plant pathogen [43]. In order to increase gene targeting efficiencies in other organisms, it is effective to inactivate NHEJ pathway, which is responsible for nonspecific integration into the genome (Fig. 5, Table 1). In eukaryotes, it was first reported in the filamentous fungus
Neurospora crassa that homologous integration efficiency was markedly increased by the inactivation of NHEJrelated genes. $N$. crassa and $S$. cerevisiae have been used in biochemical and classical genetic studies. The genome project of $N$. crassa was completed preceding any other filamentous fungi [44]. By gene disruption of the homologs of Ku70/Ku80 and DNA ligase IV, key components of NHEJ in higher eukaryotes, the frequencies of homologous integration were markedly increased, reaching almost 100\% depending on the length of the homologous region on DNA $[45,46]$. Thereafter, it became widely known that increases in genomic targeting efficiencies by the inactivation of the NHEJ pathway are common in many filamentous fungi [47-49]. The activity of NHEJ in S. cerevisiae, which preferentially utilizes a homologous recombination (HR) system for the genomic integration of foreign DNA, has not yet been elucidated. The radiosensitivity of a homozygous deletion mutant of the HDF1 gene encoding the Ku70 homolog is similar to that of the diploid wild-type strain. The phenotype of the inactivation of $H D F 1$ was observed when the RAD52 gene, encoding a key component for the HR system, was simultaneously disabled. The $\operatorname{rad} 52 \Delta h f d 1 \Delta$ double mutant was more sensitive to ionizing radiation than the rad52 $\Delta$ mutant. In haploid cells, the $h d f 1 \Delta$ strain exhibited radiosensitivity during the $\mathrm{G}_{1^{-}}$or $\mathrm{G}_{0}$-phase, and is considered to be incapable of HR because no homologous chromosome or sister chromatid is available [50]. Previous studies also reported that the expression of Lif1p and Nej1p, homologous to XRCC4 and XLF, respectively, the regulatory subunits of Lig IV, are downregulated in diploid strains [51-53]. These findings indicate that the contribution of the NHEJ pathway to DSB repair and cell survival after DNA damage is only apparent when $\mathrm{HR}$ is unavailable in S. cerevisiae. In gene targeting experiments, foreign DNA with homology to target genes, the ideal substrates for HR, are supplied. Under these conditions, S. cerevisiae may preferentially operate error-free and secure HR system rather than mutagenic NHEJ. The inactivation of the NHEJ pathway is also expected to increase gene-targeting efficiencies in higher animal cells; however, there is currently no evidence to support this in Chinese hamsters and mice [54-56]. Enhanced gene targeting was subsequently detected in NHEJ-deficient chicken DT40 and human osteosarcoma-derived U2OS cells; however, it was not as efficient as that observed in filamentous fungi $[57,58]$. These findings indicated that a microhomology-mediated end joining (MMEJ) pathway, which utilizes very short homology for the repair of DSBs [59], contributes to non-homologous recombination events in animal cells.

Homologs of most mammalian NHEJ components are also conserved in S. cerevisiae; however, this organism lacks DNA-PK ${ }_{C S}$ with DNA-dependent kinase activity, which is recruited to the DNA end by $\mathrm{Ku}$ in order to 


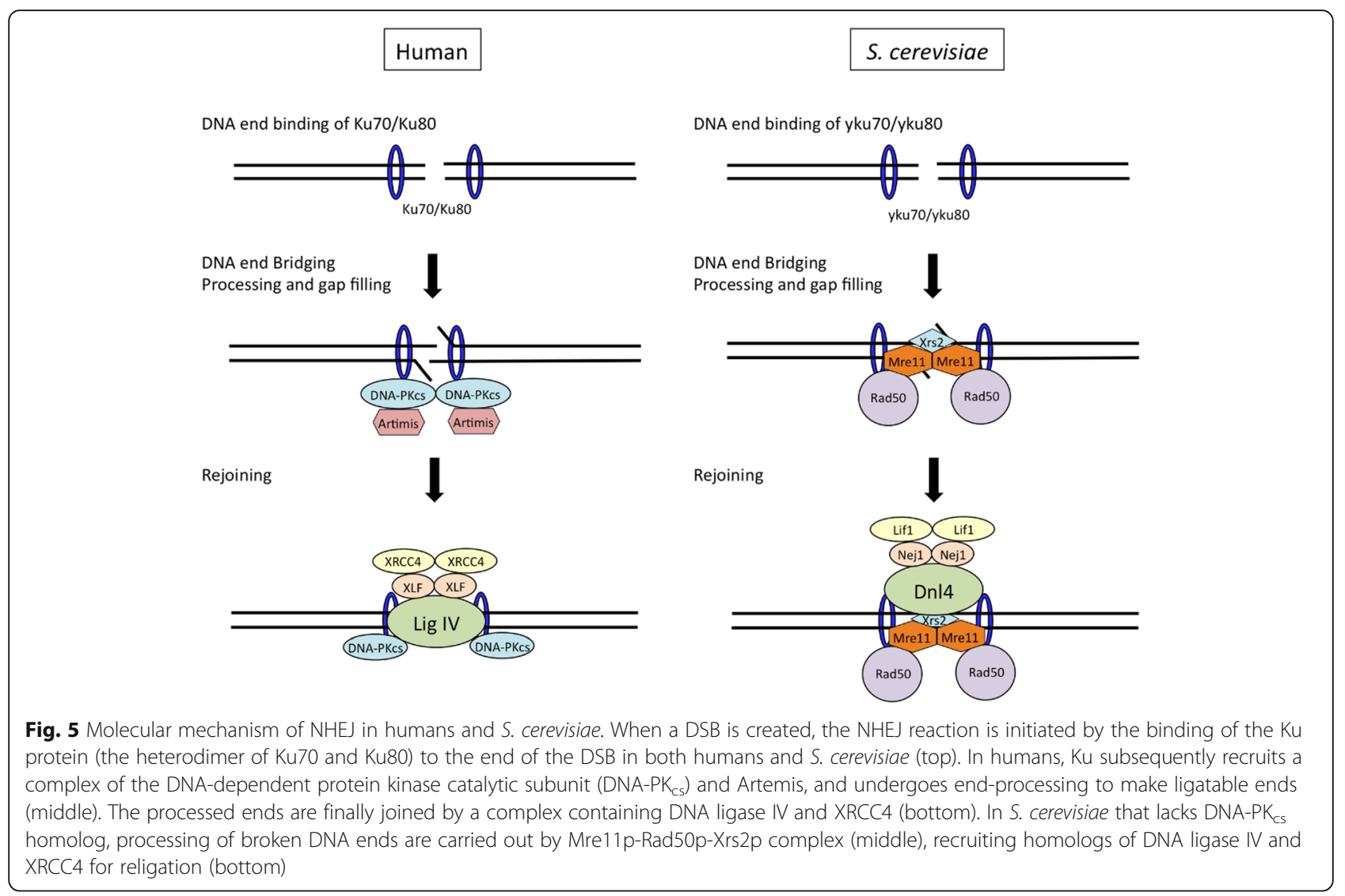

facilitate the rejoining of breaks (Table 1) [60,61]. In the human U2OS cells described above, the knockdown of DNA-PK ${ }_{C S}$ was more effective at increasing the HR frequency than that of Ku70, Ku80, or Lig IV [58]. It currently remains unclear whether the lack of DNA$\mathrm{PK}_{\mathrm{CS}}$ is related to HR selectivity in S. cerevisiae, and how DNA-PK $\mathrm{CS}_{\mathrm{CS}}$ homologs are conserved through evolution has yet to be clarified.

Other aspect that may be correlated to the prominent frequency of HR is unique molecular feature of HR proteins. In S. cerevisiae, the process of HR is carried out by

Table 1 Comparison of NHEJ factors in S. cerevisiae and mammalian cells

\begin{tabular}{ll}
\hline S. cerevisiae & Mammalian \\
\hline Yku70 (Hdf1)/Yku80 (Hdf2) & Ku70/Ku80 \\
- & DNA-PK ${ }_{\text {cs }}$ \\
Dnl4/Lif1 & Lig IV/XRCC4 \\
Nej1 & XLF \\
Pol4 & DNA polymerase $\mu$ or $\lambda$ \\
Pso2? & Artemis \\
Rad27 & FEN-1 \\
Mre11/Rad50/Xrs2 & Mre11/Rad50/Nbs1 \\
\hline
\end{tabular}

the sequential interaction of proteins in Rad52 epistasis group [62-76] (Fig. 6). Rad52p [with ssDNA annealing and binding activities to both replication protein A (RPA) and Rad51p] recruits Rad51p to the 3' ssDNA coated by RPA, and serves as a seeding site on it by displacing RPA. The Rad51p nucleoprotein filament formation on ssDNA is crucial for the subsequent strand invasion and exchange by interaction with Rad54p. The affinity of RPA for ssDNA is higher than Rad51p, thereby recombination mediator activity of Rad52p is indispensable for Rad51p-dependent HR [77, 78]. The function of these factors are widely conserved through evolution, however, the recombination mediator activity of Rad52p is unique in S. cerevisiae. BRCA2 (BReast CAncer susceptibility gene 2 ) that has little homology with $S$. cerevisiae Rad52p shares the mediator function instead of Rad52 orthologue in human $[79,80]$. Consistent with this, chicken and human cell lines lacking Rad52 show no increase in sensitivity to DNA-damaging agents and the efficiency of gene targeting is only marginally reduced [81, 82]. In contrast, S. cerevisiae rad52 mutants exhibit severe defects in all forms of HR, and recruitment of Rad51p to DSBs is strongly dependent on Rad52p [83]. These findings imply that the unique mediator function of Rad52p may also be relevant to efficient HR in S. cerevisiae. 


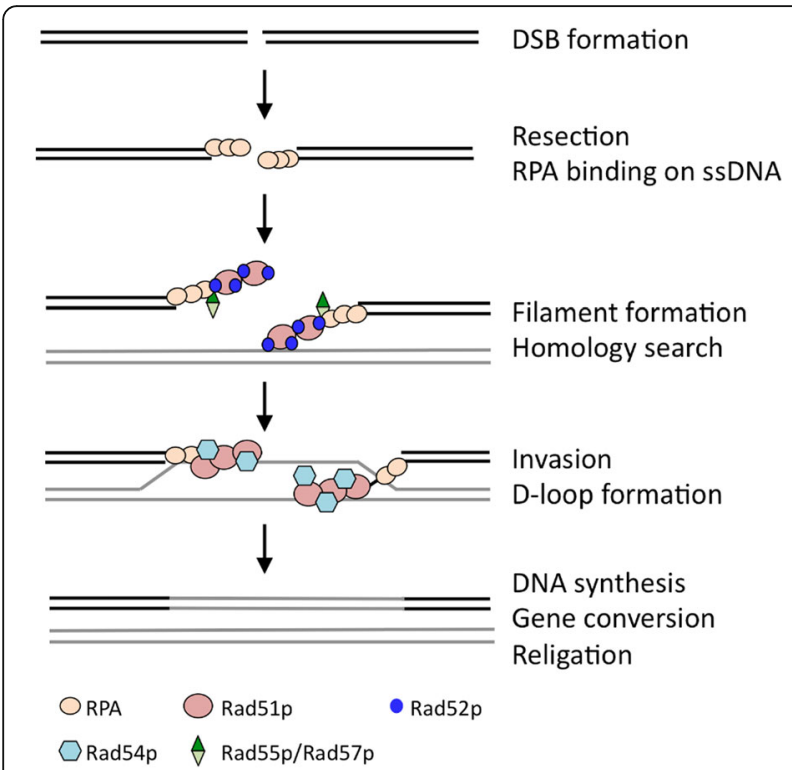

Fig. 6 Regulation of HR by factors in Rad52 epistasis group. Upon formation of a DSB, the $3^{\prime}$ single-stranded DNA (ssDNA) end is created by resection. The SSDNA tails are coated by RPA to eliminate secondary structures $[62,63]$. Rad52 $p$ that possesses multifunctions including the binding activity to both Rad51p and RPA mediates recombination by recruiting Rad51p to RPA-ssDNA complex [64, 65]. Rad52p displaces RPA to enable formation of Rad51p filament extending on the ssDNA, along with Rad55p-Rad57p heterodimer [66-70]. Subsequent genome-wide search for homologous sequences and DNA strand exchange with D-loop formation are accomplished by Rad51p-Rad54p interaction [71-76]. At the end of these processes, Rad54p catalyzes the removal of Rad51p from dsDNA to provide DNA polymerases access for initiation of the repair DNA synthesis reaction

\section{Unequal mutation frequency in the genome of $S$. cerevisiae}

In some occasions, living organisms accept genetic alterations that escaped protection mechanisms for DNA. This may lead extensive phenotypic diversity or variation in clonal populations of microorganisms, and play a role in adaptation to novel environments. The phenotypic variation or instability, which occurs via multiple mechanisms, may be a form of cellular differentiation and a stochastic means for modulating gene expression. We previously reported a case of phenotypic variation in a clinically-derived S. cerevisiae strain [84].

In addition to industrial or laboratory strains, $S$. cerevisiae has been isolated as an opportunistic pathogen from immunodeficient patients $[85,86]$. The dissected tetrad of the clinically derived diploid strain YJM421 shows Mendelian (2:2) segregation for its ability to respire on agar plates containing non-fermentable carbon sources such as glycerol and ethanol. The respiration deficiency phenotype $\left(\right.$ Pet $^{-}$) is unstable and Pet $^{-}$segregants frequently produced $\mathrm{Pet}^{+}$colonies after prolonged incubations (Fig. 7). Genetic and molecular genetic analyses of YJM421 revealed that the Pet $^{-}$phenotype is due to the

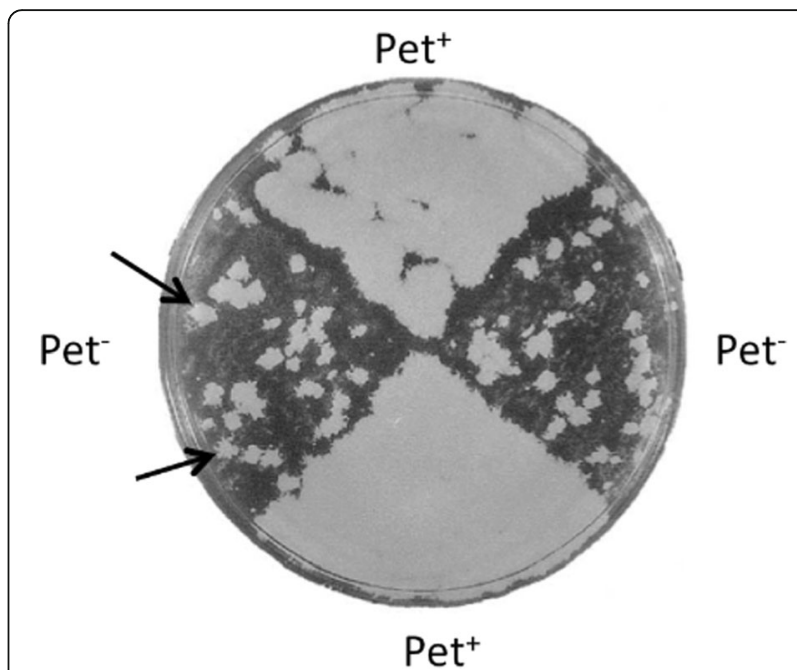

Fig. 7 Phenotypic instability of a clinically-derived strain of S. cerevisiae. The arrows indicate Pet $^{+}$colonies appearing from the Pet ${ }^{-}$progeny

ochre mutation [CAA (glutamine) to TAA at codon 39] in COX15 ORF (cox15-TAA), which encodes a protein required for cytochrome $\mathrm{C}$ oxidase assembly in mitochondria [87]. In $\mathrm{Pet}^{+}$progenies, the ochre suppressor mutation was found in SUP7 (SUP7-o), one of the tRNA-Tyr genes to suppress cox15-TAA (Fig. 8). These observations confirmed that YJM421 is homo- and heterozygous for cox15-TAA and SUP7-o, respectively, and the segregation of $\mathrm{Pet}^{+}$progenies is consistent with the segregation pattern of SUP7-o (Fig. 9).

S. cerevisiae possesses eight tRNA-Tyr genes that are dispersed on the genome (Fig. 10). We developed an easy and rapid genotyping method to identify the ochre suppressor mutation within the eight tRNA-Tyr loci, and examined the frequencies of the tyrosine-inserting ochre suppressor mutation (SUP-o) and reversion of cox15-TAA. More than 40 spontaneous Pet $^{+}$mutants were isolated from each of the three parental Pet $^{-}$strains, diploid and haploid strains derived from YJM421 and a haploid laboratory strain, and mutants were genotyped to identify the tRNA-Tyr locus mutated to SUP-o. In cases in which all tRNA-Tyr loci were the wild-type, cox15-TAA was sequenced. In all 129 Pet $^{+}$mutants, cox15-TAA reversion was only observed in three mutants, while the SUP-o mutation at one of the eight tRNA-Tyr loci was responsible for conferring the $\mathrm{Pet}^{+}$phenotype in others. There were seven patterns of single base-pair substitution mutations that convert a TAA ochre codon to one of the seven sense codons, and all of them resulted in a functional Cox15p (Fig. 11) [84]. Furthermore, although SUP-o mutations at other tRNA loci may suppress cox15-TAA, these mutations occurred almost exclusively at tRNA-Tyr loci in spontaneous $\mathrm{Pet}^{+}$mutants. The distribution of 42 SUP-o mutants within tRNA-Tyr loci isolated from each of the three 


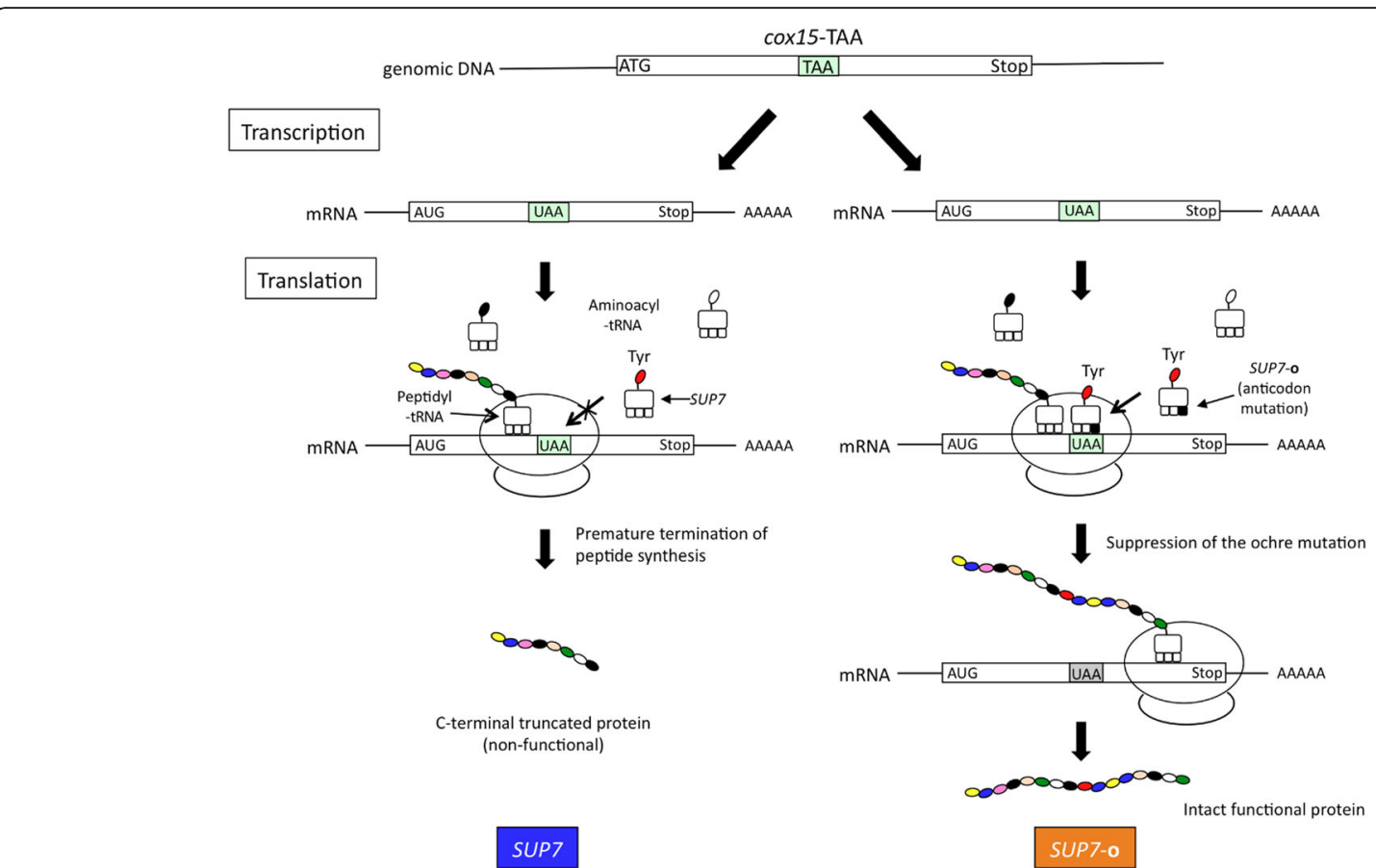

Fig. 8 Molecular mechanism of the suppression of the cox15-TAA mutation by SUP7-o. In a cell containing wild-type SUP7, ribosome ceases translation elongation when it reaches the in-frame ochre mutation to produce a C-terminal truncated non-functional polypeptide (left). When an anticodon mutation occurs in the SUP7 gene, the ochre suppressor SUP7-o inserts tyrosine to suppress the ochre codon, and enables translation elongation to proceed in order to produce a full-length polypeptide (right)

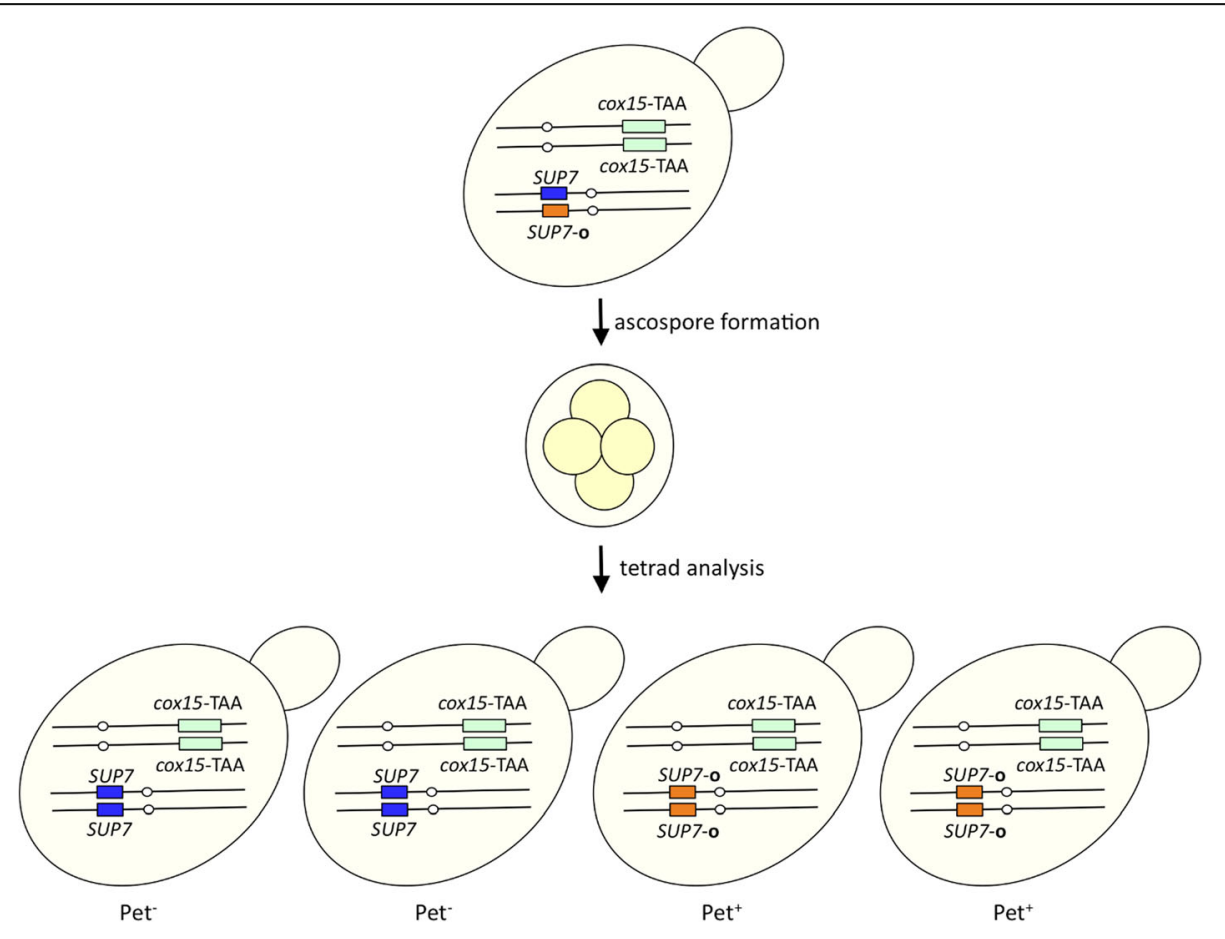

Fig. 9 Segregation pattern of mutations and the Pet phenotype in progenies of YJM421YJM421 was homozygous for cox15-TAA and heterozygous for SUP7-o. The Pet ${ }^{+}$phenotype and SUP7-o were co-segregated in progenies [84]. YJM421 is a homothallic strain in which haploid ascospores undergo mating-type switching to become diploid during propagation after germination 


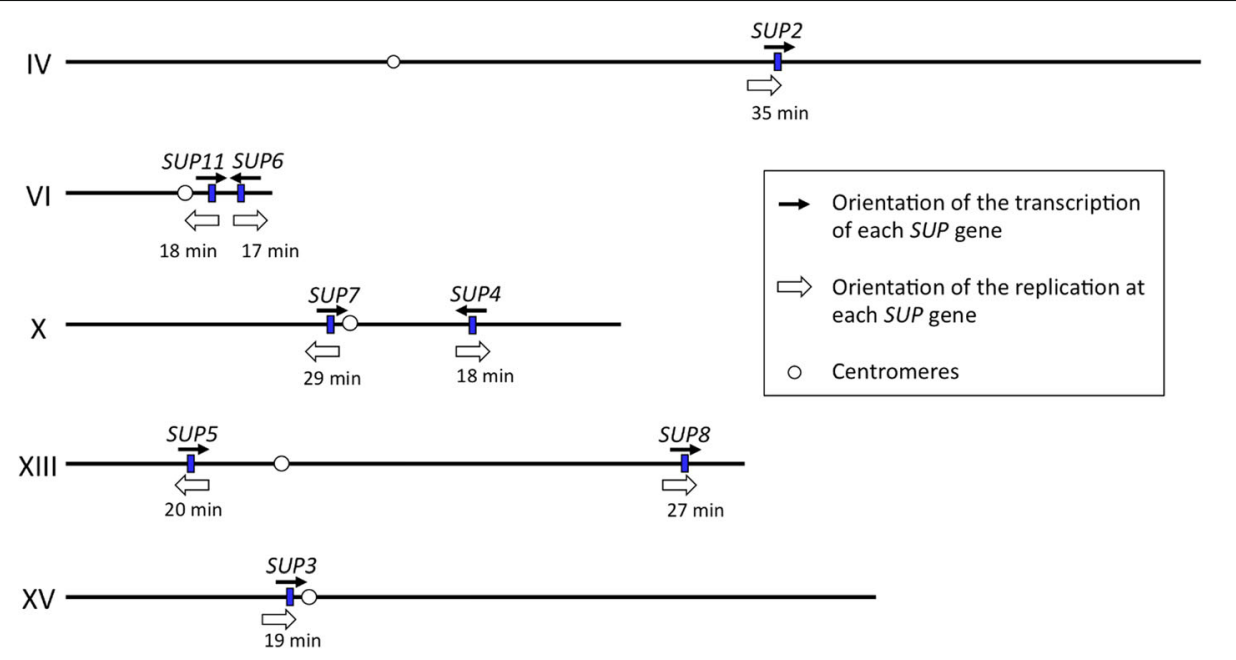

Fig. 10 Chromosomal localization of tRNA-Tyr genes. Eight tRNA-Tyr genes are dispersed in the genome. The orientation of transcription of the each SUP gene is shown by black arrow. Direction of DNA replication is represented by open arrow with timing (minutes) during S-phase based on data reported by Raghuraman et al. [112]

parental Pet $^{-}$strains was summarized in Table 2. Aside from a single base-pair polymorphism within the intron, all members of the tRNA-Tyr gene family had identical sequences. We observed biased mutation frequencies among them that were highly significant in the $\chi^{2}$ test $(p<0.001)$. The mutation frequency at the SUP6 locus (approximately $30 \%)$ was markedly higher than the average frequency, while those at SUP2 ISUP8 and SUP3 loci were markedly lower ( $1.6 \%$ and $5.6 \%$, respectively). Our study on $S$. cerevisiae revealed mutation rate variations at different loci, suggesting that the mutation rate is not uniform across the genome.

All three parental strains showed similar results with respect to mutation rate variations within tRNA-Tyr genes, which suggest that this is a common phenomenon in S. cerevisiae rather than being background-dependent (clinically-

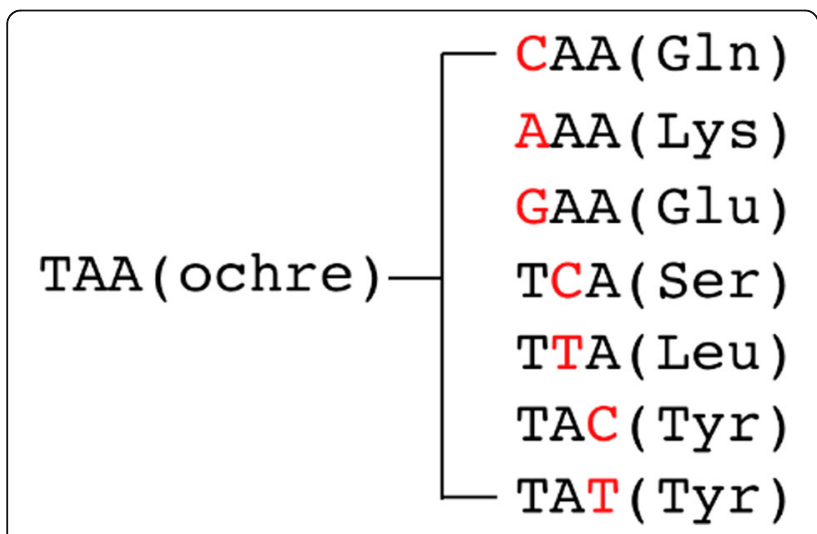

Fig. 11 Patterns of reversions from the cox15-TAA mutation. The nucleotide written in red is the mutated position with coding amino acids in parentheses. Cox15 proteins carrying these reversions are functional [84] derived strain vs. laboratory strain). In order to deduce the mechanism underlying the position effects on mutation frequencies, we examined the relationship between tRNA-Tyr locus-specific mutation frequencies and multiple factors. We examined the suppression efficiencies of SUP-o mutants using a reporter plasmid that is a measurable readthrough of the ocher mutation. We also searched previous studies; the distances of tRNA-Tyr genes from the centromere or telomere, the localization of transposons, the expression levels of flanking genes, the timing of replication, or the rate of replication fork movement, and found that none correlated with the biased mutation frequency. However, it is interesting to note that SUP2, SUP3, and SUP8, the three loci with the lowest mutation frequencies, were all transcribed in the same direction as replication forks. In contrast, SUP4, SUP5, SUP7, and SUP11, the four loci with average mutation frequencies, as well as SUP6, the locus with the highest mutation frequency, were all transcribed in the opposite direction to replication forks (Fig. 10). This finding suggests that gene orientation relative to the direction of replication may be a factor explaining locus-specific mutation frequencies. However, one or more additional factors may contribute to biased mutation frequencies [84].

The unequal mutation frequency/rate across the $S$. cerevisiae genome was verified in studies by other groups $[88,89]$. In order to detect frameshift mutation rates, Hawk et al. [88] constructed 10 isogenic yeast strains carrying the fusion reporter gene, the uracil synthetic gene URA3, including in-frame microsatellite GT-repeats (URA3-GT) at different locations in the genome. They examined insertions at the SUP2 and SUP6 loci showing the lowest and highest mutation frequencies, respectively, in order to convert to the ochre suppressor [84]. The rate of frameshift mutations was 16-fold different among these 
Table 2 Number of independently isolated SUP-o mutants

\begin{tabular}{|c|c|c|c|c|c|c|c|c|}
\hline Strain & SUP2-o & SUP3-o & SUP4-o & SUP5-o & SUP6-o & SUP7-o & SUP8-o & SUP11-o \\
\hline YSA3 & 1 & 4 & 7 & 4 & 11 & 7 & 1 & 7 \\
\hline V1-1- & 1 & 2 & 3 & 8 & 11 & 7 & 1 & 9 \\
\hline S183 & 0 & 1 & 10 & 5 & 17 & 5 & 0 & 4 \\
\hline Total & 2 & 7 & 20 & 17 & 39 & 19 & 2 & 20 \\
\hline
\end{tabular}

YSA3 and V1-1- are diploid and haploid, respectively, derived from the YJM421 strain, and S183 is the haploid strain in the laboratory background (data referred from [84])

strains, and this rate was the highest at the SUP6 locus, which was 9-fold higher than that at the SUP2 locus. These findings suggest that frameshift mutations as well as base substitution mutations preferably occur at the SUP6 locus. In mismatch-repair (MMR)-deficient strains that lack Msh2p, the rates of frameshift mutations were elevated at all loci tested; however, differences among the mutation rates at different genomic sites were markedly less than those observed in the $\mathrm{MMR}^{+}$wild-type strains (from 16-fold to 2-fold). These findings indicate that a difference in MMR efficiency is one of the factors affecting the mutation rates at different loci in the genome (Fig. 12a) [88].

Lang et al. [89] examined the relationship between chromosomal localizations and spontaneous mutation rates by measuring the mutation rate of the URA3 gene integrated at 43 different locations tiled across chromosome VI in S. cerevisiae. Two tRNA-Tyr genes, SUP6 and SUP11 were localized on chromosome VI. They showed that the mutation rate varied 6-fold across a single chromosome. Variations in the mutation rate correlated with replication timing, with earlier-replicating regions having lower mutation rates and regions replicated in the late $S$-phase having higher mutation rates. The manipulation of replication timing by deleting the earliest and most efficient origin ARS607 increased the mutation rate at the URA3 reporter gene by $30 \%$. Furthermore, the disruption of gene encoding translesion synthesis (TLS) DNA polymerase Rev1p resulted in a 4.8 -fold reduction in the mutation rate at the

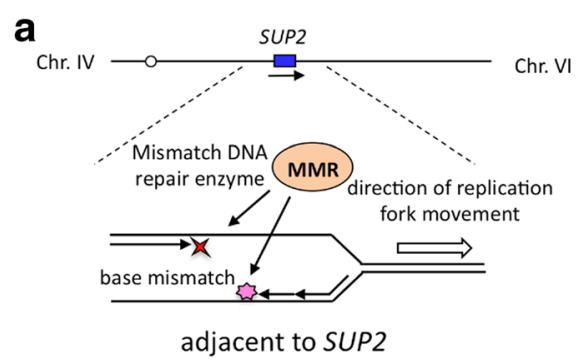

b
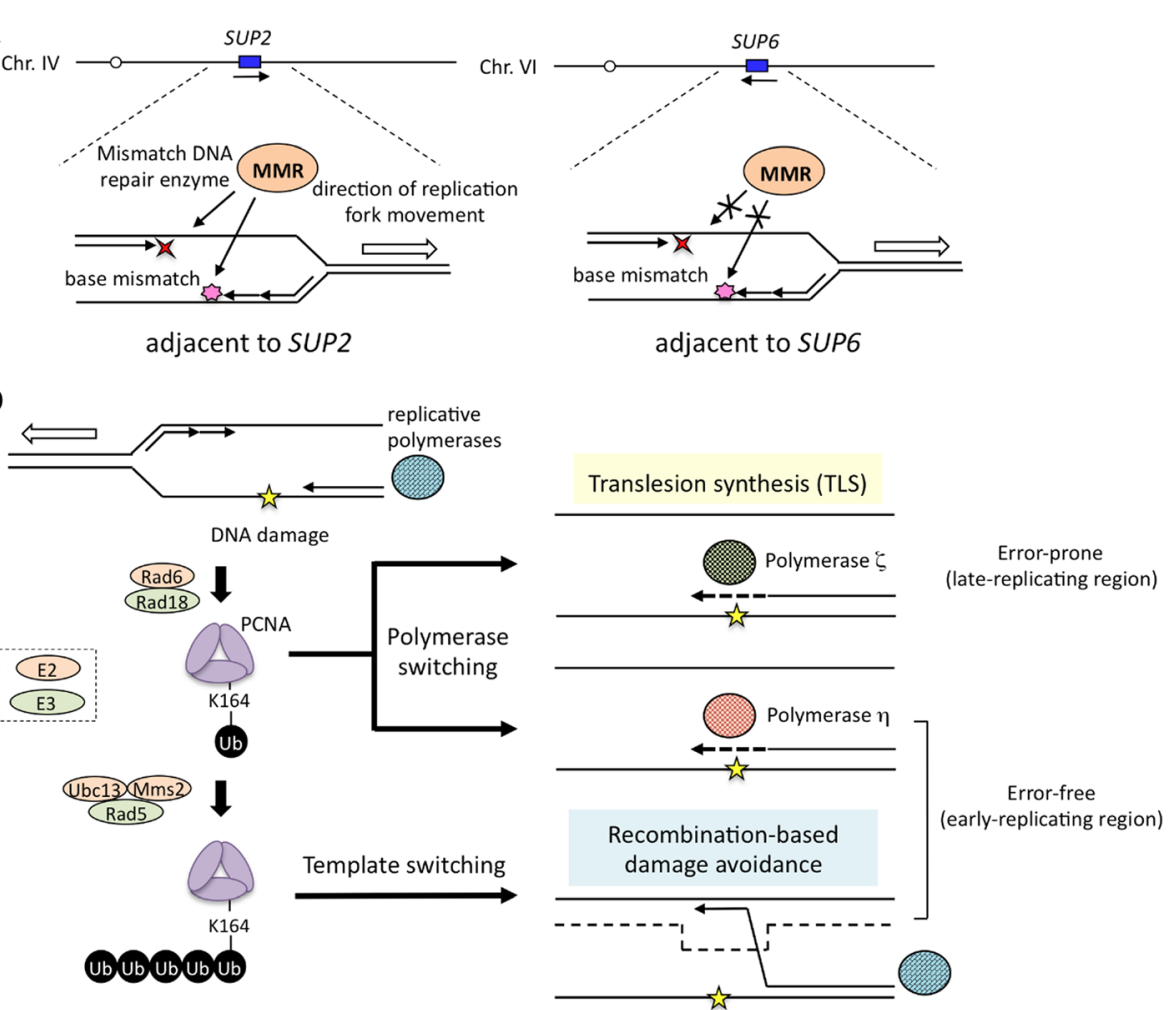

Fig. 12 Putative mechanisms that contribute to the bias of the mutation rate in the genome. a Difference in the efficiency of the mismatch DNA repair. Mismatch base-pairing by damage-induced replication errors is rapidly repaired in the region adjacent to SUP2, whereas efficiency is lower in the SUP6 adjacent region [88]. $\mathbf{b}$ Involvement of replication timing on the chromosome. Fidelity of DNA damage bypass may be determined by availability of TLS polymerases (error-free or error-prone) and induction of Rad5p-mediated recombination-based template switching during cell cycle, those are correlated with ubiquitination status of PCNA (see text for detail) [89, 90, 92-96] 
late-replicating locus with the high mutation rate [89]. TLS polymerases have the ability to synthesize DNA strand past lesions with markedly higher error rates than replicative polymerases [90, 91]. DNA damage-induced replication fork stall triggers monoubiquitination of proliferating cell nuclear antigen (PCNA encoded by POL30 gene) at K164, which is catalyzed by the E2 ubiquitin (Ub) conjugating enzyme Rad6p and the E3 Ub ligase Rad18p (Rad6p/Rad18p complex) [92]. Monoubiquitinated PCNA is known to activate TLS polymerases Rev1p and Rad30p (polymerase $\eta$ ) [93, 94]. Rev1p assists to recruit other TLS polymerases Rev3p and Rev7p consisting of error-prone polymerase $\zeta$, in addition to its own TLS polymerase activity [90]. Rev1p is not expressed until the late $\mathrm{S}$-phase, while error-free polymerase $\eta$ is constantly expressed [95]. Mutation rate bias associated with replication timing may be determined by the availability of TLS polymerases during cell cycle. DNA replication fork stall also induces recombinationbased template switching, another postreplication repair pathway, involved in polyubiquitinated PCNA at the same K164 residue catalyzed by Ubc13p-Mms2p-Rad5p Ub E2E3 complex [92]. Rad5p also has DNA helicase activity specific for replication fork regression, which is thought to facilitate sister strand recombination [96]. These findings suggest that DNA damage generated in early-replicating regions may be bypassed by recombination-based template switching or polymerase $\eta$-involved error-free TLS by polymerase switching, while damaged bases in late-replicating regions are more likely to be subjected to mutagenic TLS by polymerase $\zeta$, (Fig. 12b) [89].

These findings are based on the measurement of spontaneous mutation rates. It is of interest to examine how mutation rates change when induced by ionizing radiation and various DNA-damaging agents.

\section{Nonsense suppressors and phenotypic variations: Nonsense suppressors are agents for environmental adaptation?}

The mutations that convert tRNA-Tyr genes to ochre suppressors described above confer phenotypic variations to Pet $^{+}$cells. The tRNA-Tyr SUP-o and amber suppressor $S U P-\mathbf{a}$ affect cell proliferation, ascospore formation, and sensitivity to high osmolality. Variations in phenotypes correlated with the suppression efficiency of each SUP-o/SUPa mutant [84, 97-99]. Therefore, nonsense suppressors may act on nonsense mutations such as the termination codons of other genes and natural nonsense mutations that spontaneously arose within protein coding regions during the evolutionary process, as well as nonsense mutation

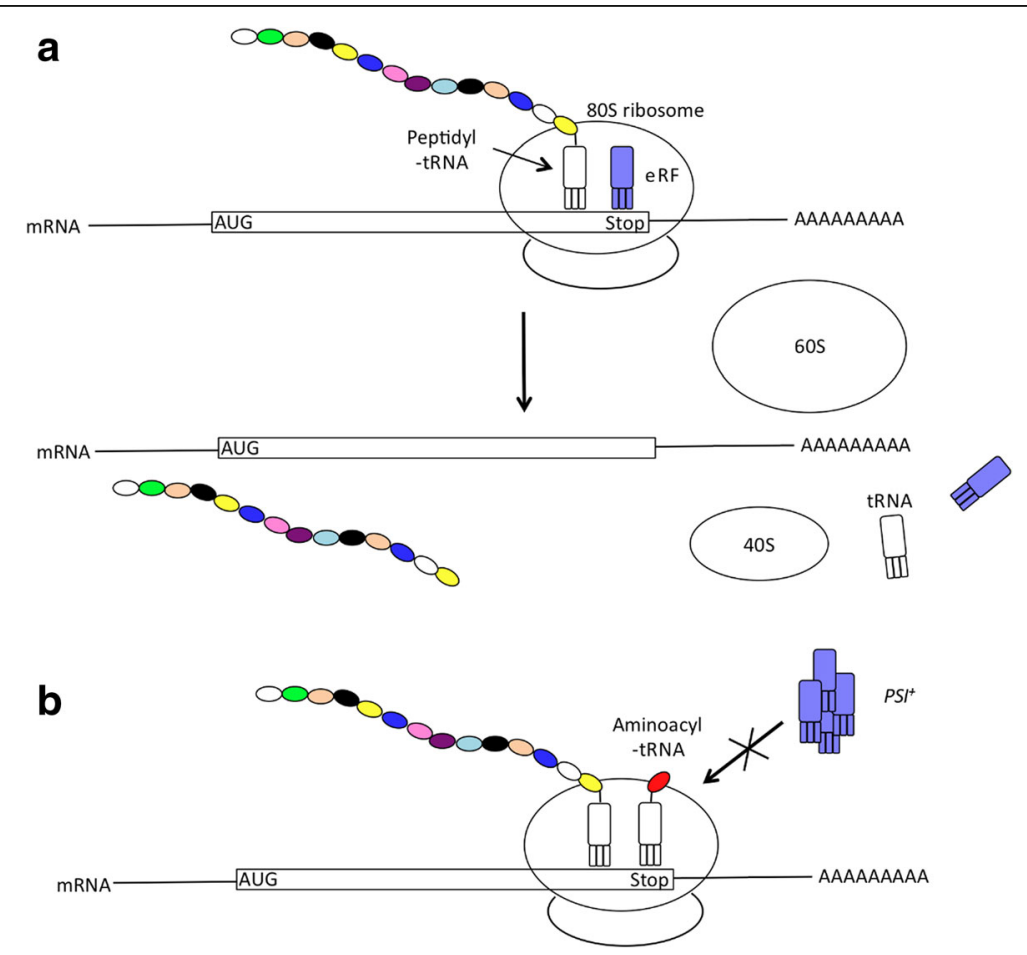

Fig. 13 Decrease in translation termination efficiency by the $\psi$ (PSI) factor. a Translation termination in normal cells. When actively translating 805 ribosomes reach the termination codon on mRNA, eRF instead of aminoacyl-tRNA enters into the A site of ribosomes. Translation then ceases, leading to the dissociation of the nascent polypeptide, tRNA, and eRF from ribosomes. Ribosomes themselves also dissociate to $40 \mathrm{~S}$ and $60 \mathrm{~S}$ subunits. b $\mathrm{PSI}^{+}$generation by the aggregation of Sup35. Since functional Sup35 is depleted, the efficiency of translation termination is decreased, allowing the entry of aminoacyl-tRNA into the ribosome A site. Ribosomes continue to translate the 3'-UTR of mRNA beyond the intrinsic termination codon. This may cause the C-terminal extension of nascent polypeptides, as well as the suppression of natural nonsense mutations 
reporters (in the case of our study, a cox15-TAA mutation). The translational readthrough of termination codons by nonsense suppressors extended the $C$ terminus of nascent polypeptides, which may modulate the activities of cellular proteins [100]. The suppression of natural nonsense mutations may lead to the production of full-length functional proteins from nonsense-containing transcripts (Fig. 8) [84]. Nonsense suppressors may alter global gene expression profiles, such as DNA repair, DNA damage response, and metabolism, in addition to ascospore formation and high osmolality tolerance, as described above.

The readthrough of nonsense codons also occurs by mutations in the SUP35 and SUP45 genes, which encode the translational termination factors (eukaryotic release factor: eRF) eRF3 and eRF1, respectively. Sup35p and Sup45p interact to form functional eRF [101]. The factor $\psi(P S I)$, which was identified as a modifier of nonsense suppression in some strains of $S$. cerevisiae, is a nonMendelian (cytoplasmic) element [102]. A subsequent study revealed that Sup35p itself forms amyloid-like fiber-shaped aggregates when overproduced. This form of Sup35p is referred as $\mathrm{PSI}^{+}$, a prion form in S. cerevisiae [103]. In these mutants, the recognition of a termination codon is impaired by the depletion of functional eRF, leading to continuous translation beyond termination codons (Figs. 8 and 13). While the suppression efficiencies of nonsense codons by aberrant eRFs are lower than the nonsense suppressor form of tRNA-Tyr, aberrant eRFs are omnipotent suppressors that act on all types of nonsense codons (ochre, amber, and opal) $[104,105]$. The conversion of Sup35p to $P S I^{+}$gave rise to phenotypic variations associated with translation termination efficiency upon adaptation to environmental conditions [106-110].

The numbers of each termination codon assigned for all 6221 ORFs are 2948 for ochre (TAA) (47.4\%), 1416 for amber (TAG) (22.8\%), and 1857 for opal (TGA) (29.8\%) [111]. The numbers of genes affected by nonsense readthrough will vary depending on the type and efficiency of the nonsense suppressor, which may confer diverse phenotypes. The acquisition of phenotypic variations by nonsense suppressors may be advantageous for adaptation to environmental stresses and a strategy to maintain the species. It may also be a powerful driving force for evolution.

\section{Conclusions}

The generation of DNA lesions impairing accuracy of genetic information are surveyed and repaired by evolutionarily conserved mechanisms in eukaryotes, with somewhat divergent machineries and/or activities specific to $S$. cerevisiae. The evolution of molecular architecture may be elucidated by cross-species comparison among related organisms. Meanwhile, genetic alteration that can confer substantial phenotypic variation plays significant roles for adaptation against hazardous environmental stresses. Yeast genetics will be a powerful tool to unveil the molecular mechanisms underlying each case of environmental adaptation.

In $S$. cerevisiae, many strains were isolated from different origins such as brewery, laboratory, and clinical origins, and a genome project was accomplished for each of these strains [111]. Similarly, genome projects for yeast species in the group of Saccharomyces, or "budding yeast" in a broad sense, such as dimorphic fungi Candida albicans and Cryptococcus neoformans that grow by budding in a part of the life cycle, have also been performed. Abundant resources are now available, and comparative genomics have contributed to advances in yeast research. By taking advantage of these circumstances, post-genome research to approach as yet unrevealed mysteries of life may be facilitated in yeast. We expect exciting research on the unique features of $S$. cerevisiae to advance in the future.

\section{Abbreviations \\ dNTP: Deoxyribonucleoside triphosphate; DSB: Double-strand break; eRF: Eukaryotic release factor; HR: Homologous recombination; HU: Hydroxyurea; IR: lonizing radiation; LET: Linear energy transfer; MMEJ: Microhomology-mediated end joining; MMR: Mismatch repair; MMS: Methyl methanesulfonate; NHEJ: Non-homologous end joining; PCNA: Proliferating cell nuclear antigen; RNAi: RNA interference; RNR: Ribonucleotide reductase; ROS: Reactive oxygen species; \\ RPA: Replication protein A; TLS: Translesion synthesis; Ub: Ubiquitin; UV: Ultraviolet}

\section{Acknowledgements \\ We are grateful to Toshiaki Harashima for critical reading and valuable comments on this review. SIH and TY devote this review to Koki Yamamoto who sadly passed away at the age of 22 in September 2014 during his thesis study on S. cerevisiae in our laboratory. All members in the laboratory express our sincere condolences to his family.}

\section{Funding}

The publication of this review is supported by a basic research grant from Osaka Prefecture University.

Availability of data and materials Not applicable.

\section{Authors' contributions}

$\mathrm{SIH}$ prepared the primary manuscript. TY proofread the manuscript and gave comments to $\mathrm{SIH}$. Both authors read and approved the final manuscript.

Ethics approval and consent to participate

Not applicable.

Consent for publication

Not applicable.

Competing interests

The authors declare that they have no competing interests.

\section{Publisher's Note}

Springer Nature remains neutral with regard to jurisdictional claims in published maps and institutional affiliations. 
Received: 28 August 2017 Accepted: 26 October 2017 Published online: 01 December 2017

\section{References}

1. Goffeau A, Barrell BG, Bussey H, Davis RW, Dujon B, Feldmann H, Galibert F, Hoheisel JD, Jacq C, Johnston M, et al. Life with 6000 genes. Science. 1996; 274:546-67.

2. Malumbres M, Barbacid M. Cell cycle, CDKs and cancer: a changing paradigm. Nat Rev Cancer. 2009;9:153-66.

3. Mendenhall MD, Hodge AE. Regulation of Cdc28 cyclin-dependent protein kinase activity during the cell cycle of the yeast Saccharomyces cerevisiae. Microbiol Mol Biol Rev. 1998;62:1191-243.

4. Sipiczki M. Where does fission yeast sit on the tree of life? Genome Biol. 2000;1:1011.1-4

5. Pluta AF, Mackay AM, Ainsztein AM, Goldberg IG, Earnshaw WC. The centromere: hub of chromosomal activities. Science. 1995;270:1591-4.

6. Wood V, Gwilliam R, Rajandream MA, Lyne M, Lyne R, Stewart A, Sgouros J, Peat N, Hayles J, Baker S, et al. The genome sequence of Schizosaccharomyces pombe. Nature. 2002;415:871-80.

7. Roguev A, Bandyopadhyay S, Zofall M, Zhang K, Fischer T, Collins SR, Qu H, Shales M, Park H-O, Hayles J, et al. Conservation and rewiring of functional modules revealed by an epistasis map in fission yeast. Science. 2008;322:405-10.

8. Fu Y, Pastushok L, Xiao W. DNA damage-induced gene expression in Saccharomyces cerevisiae. FEMS Microbiol Rev. 2008;32:908-26.

9. Shiloh Y. ATM and ATR: networking cellular responses to DNA damage. Curr Opin Genet Dev. 2001:11:71-7.

10. Sanchez Y, Desany BA, Jones WJ, Liu Q, Wang B, Elledge SJ. Regulation of RAD53 by the ATM-like kinases MEC1 and TEL1 in yeast cell cycle checkpoint pathways. Science. 1996;271:357-60.

11. Huang M, Zhou Z, Elledge SJ. The DNA replication and damage checkpoint pathways induce transcription by inhibition of the Crt1 repressor. Cell. 1998; 94:595-605.

12. Zaim J, Eb S, Kierzek AM. Identification of new genes regulated by the Crt1 transcription factor, an effector of the DNA damage checkpoint pathway in Saccharomyces cerevisiae. J Biol Chem. 2005;280:28-37.

13. Basrai MA, Velculescu VE, Kinzler KW, Hieter P. NORF5/HUG1 is a component of the MEC1-mediated checkpoint response to DNA damage and replication arrest in Saccharomyces cerevisiae. Mol Cell Biol. 1999;19:7041-9.

14. Jia X, Zhu Y, Xiao W. A stable and sensitive genotoxic testing system based on DNA damage induced gene expression in Saccharomyces cerevisiae. Mut Res. 2002;519:83-92.

15. Caba E, Dickinson DA, Warnes GR, Aubrecht J. Differentiating mechanisms of toxicity using global gene expression analysis in Saccharomyces cerevisiae. Mut Res. 2005;575:34-46.

16. Boronat S, Pina B. Development of RNR3- and RAD54-GUS reporters for testing genotoxicity in Saccharomyces cerevisiae. Anal Bioanal Chem. 2006;386:1625-32.

17. Benton MG, Glasser NR, Palecek SP. The utilization of a Saccharomyces cerevisiae HUGIP-GFP promoter-reporter construct for the selective detection of DNA damage. Mut Res. 2007;633:21-34

18. Mizukami-Murata S, Iwahashi H, Kimura S, Nojima K, Sakurai Y, Saitou T, Fujii N, Murata Y, Suga S, Kitagawa K, et al. Genome-wide expression changes in Saccharomyces cerevisiae in response to high-LET ionizing radiation. Appl Biochem Biotechnol. 2010;162:855-70.

19. Chabes A, Georgieva B, Domkin V, Zhao X, Rothstein R, Thelander L. Surviva of DNA damage in yeast directly depends on increased dNTP levels allowed by relaxed feedback inhibition of ribonucleotide reductase. Cell. 2003;112:391-401.

20. Håkansson P, Dahl L, Chilkova O, Domkin V, Thelander L. The Schizosaccharomyces pombe replication inhibitor Spd1 regulates ribonucleotide reductase activity and dNTPs by binding to the large Cdc22 subunit. J Biol Chem. 2006;281:1778-83.

21. Håkansson P, Hofer A, Thelander L. Regulation of mammalian ribonucleotide reduction and dNTP pools after DNA damage and in resting cells. J Biol Chem. 2006;281:7834-41.

22. Nordlund P, Reichard P. Ribonucleotide reductases. Annu Rev Biochem. 2006;75:681-706

23. Chabes A, Domkin V, Larsson G, Liu A, Gräslund A, Wijmenga S, Thelander L. Yeast ribonucleotide reductase has a heterodimeric iron-radical-containing subunit. Proc Natl Acad Sci U S A. 2000;97:2474-9.

24. Huang M, Elledge SJ. Identification of RNR4, encoding a second essential small subunit of ribonucleotide reductase in Saccharomyces cerevisiae. Mol Cell Biol. 1997;17:6105-13.
25. Wang PJ, Chabes A, Casagrande R, Tian XC, Thelander L, Huffaker TC. Rnr4p, a novel ribonucleotide reductase small-subunit protein. Mol Cell Biol. 1997; 17:6114-21.

26. Elledge SJ, Davis RW. Two genes differentially regulated in the cell cycle and by DNA-damaging agents encode alternative regulatory subunits of ribonucleotide reductase. Genes Dev. 1990;4:740-51.

27. Yao R, Zhang Z, An X, Bucci B, Perlstein DL, Stubbe J, Huang M. Subcellular localization of yeast ribonucleotide reductase regulated by the DNA replication and damage checkpoint pathways. Proc Natl Acad Sci U S A 2003;100:6628-33.

28. Byrne KP, Wolfe KH. The yeast gene order browser: combining curated homology and syntenic context reveals gene fate in polyploid species. Genome Res. 2005:15:1456-61.

29. Lee YD, Wang J, Stubbe J, Elledge SJ. Dif1 is a DNA-damage-regulated facilitator of nuclear import for ribonucleotide reductase. Mol Cell. 2008:32:70-80.

30. Wu X, Huang M. Dif1 controls subcellular localization of ribonucleotide reductase by mediating nuclear import of the R2 subunit. Mol Cell Biol. 2008;28:7156-67.

31. Zhao X, Muller EGD, Rothstein R. A suppressor of two essential checkpoint genes identifies a novel protein that negatively affects dNTP pools. Mol Cell. 1998;2:329-40.

32. Chabes A, Domkin V, Thelander L. Yeast Sml1, a protein inhibitor of ribonucleotide reductase. J Biol Chem. 1999:274:36679-83.

33. Zhao X, Georgieva B, Chabes A, Domkin V, Ippel JH, Jr S, Wijmenga S, Thelander L, Rothstein R. Mutational and structural analyses of the ribonucleotide reductase inhibitor Sml1 define its Rnr1 interaction domain whose inactivation allows suppression of mecl and rad53 lethality. Mol Cell Biol. 2000;20:9076-83.

34. Zhao X, Chabes A, Domkin V, Thelander L, Rothstein R. The ribonucleotide reductase inhibitor $\mathrm{Sml1}$ is a new target of the Mec1/Rad53 kinase cascade during growth and in response to DNA damage. EMBO J. 2001;20:3544-53.

35. Andreson BL, Gupta A, Georgieva BP, Rothstein R. The ribonucleotide reductase inhibitor, $S \mathrm{ml} 1$, is sequentially phosphorylated, ubiquitylated and degraded in response to DNA damage. Nucleic Acids Res. 2010;38:6490-501.

36. Nestoras K, Mohammed AH, Schreurs A-S, Fleck O, Watson AT, Poitelea M, O'Shea C, Chahwan C, Holmberg C, Kragelund BB, et al. Regulation of ribonucleotide reductase by Spd1 involves multiple mechanisms. Genes Dev. 2010:24:1145-59.

37. Kim E, Siede W. Phenotypes associated with Saccharomyces cerevisiae Hug1 protein, a putative negative regulator of dNTP levels, reveal similarities and differences with sequence-related Dif1. J Microbiol. 2011;49:78-85.

38. Ainsworth WB, Hughes BT, WC A, Sakelaris S, Kerscher O, Benton MG, Basrai MA. Cytoplasmic localization of Hug1p, a negative regulator of the MEC1 pathway, coincides with the compartmentalization of Rnr2p-Rnr4p. Biochem Biophys Res Commun. 2013;439:443-8.

39. Meurisse J, Bacquin A, Richet N, Charbonnier J-B, Ochsenbein FO, Peyroche A. Hug1 is an intrinsically disordered protein that inhibits ribonucleotide reductase activity by directly binding Rnr2 subunit. Nucleic Acids Res. 2014; 42:13174-85.

40. Xu H, Fairman JW, Wijerathna SR, Kreischer NR, LaMacchia J, Helmbrecht E, Cooperman BS, Dealwis C. The structural basis for peptidomimetic inhibition of eukaryotic ribonucleotide reductase: a conformationally flexible pharmacophore. J Med Chem. 2008:51:4653-9.

41. Haber JE. Partners and pathways: repairing a double-strand break. Trends Genet. 2000;16:259-64.

42. Takita Y, Takahara M, Nogami S, Anraku Y, Ohya Y. Applications of the long and accurate polymerase chain reaction method in yeast molecular biology: direct sequencing of the amplified DNA and its introduction into yeast. Yeast. 1997;13:763-8.

43. Steiner S, Wendland J, Wright MC, Philippsen P. Homologous recombination as the main mechanism for DNA integration and cause of rearrangements in the filamentous ascomycete Ashbya gossypii. Genetics. 1995;140:973-87.

44. Galagan JE, Calvo SE, Borkovich KA, Selker EU, Read ND, Jaffe D, FitzHugh W, Ma LJ, Smirnov S, Purcell S, et al. The genome sequence of the filamentous fungus Neurospora crassa. Nature. 2003:422:859-68.

45. Ninomiya $Y$, Suzuki $K$, Ishii $C$, Inoue $H$. Highly efficient gene replacements in Neurospora strains deficient for nonhomologous end-joining. Proc Natl Acad Sci U S A. 2004:101:12248-53.

46. Ishibashi K, Suzuki K, Ando Y, Takakura C, Inoue H. Nonhomologous chromosomal integration of foreign DNA is completely dependent on MUS-53 (human Lig4 homolog) in Neurospora. Proc Natl Acad Sci U S A. 2006;103:14871-6. 
47. Krappmann S. Gene targeting in filamentous fungi: the benefits of impaired repair. Fungal Biol Rev. 2007;21:25-9.

48. Meyer $V$. Genetic engineering of filamentous fungi-progress, obstacles and future trends. Biotechnol Adv. 2008;26:177-85.

49. Kück U, Hoff B. New tools for the genetic manipulation of filamentous fungi. Appl Microbiol Biotechnol. 2010;86:51-62.

50. Siede W, Friedl AA, Dianova I, Eckardt-Schupp F, Friedberg EC. The Saccharomyces cerevisiae Ku autoantigen homologue affects radiosensitivity only in the absence of homologous recombination. Genetics. 1996;142:91-102.

51. Valencia M, Bentele M, Vaze MB, Herrmann G, Kraus E, Lee SE, Schar P, Haber JE. NEJ1 controls non-homologous end joining in Saccharomyces cerevisiae. Nature. 2001;414:666-9.

52. Frank-Vaillant M, Marcand S. NHEJ regulation by mating type is exercised through a novel protein, Lif2p, essential to the ligase IV pathway. Genes Dev. 2001;15:3005-12.

53. Kegel A, Sjostrand JO, Astrom SU. Nej1p, a cell type-specific regulator of nonhomologous end joining in yeast. Curr Biol. 2001;11:1611-7.

54. Liang F, Romanienko PJ, Weaver DT, Jeggo PA, Jasin M. Chromosomal double-strand break repair in Ku80-deficient cells. Proc Natl Acad Sci U S A. 1996;93:8929-33.

55. Pierce AJ, Hu P, Han M, Ellis N, Jasin M. Ku DNA end-binding protein modulates homologous repair of double-strand breaks in mammalian cells. Genes Dev. 2001;15:3237-42.

56. Dominguez-Bendala J, Masutani M, McWhir J. Down-regulation of PARP-1, but not of Ku80 or DNA-PKcs, results in higher gene targeting efficiency. Cell Biol Int. 2006;30:389-93.

57. liizumi S, Kurosawa A, So S, Ishii Y, Chikaraishi Y, Ishii A, Koyama H, Adachi N. Impact of non-homologous end-joining deficiency on random and targeted DNA integration: implications for gene targeting. Nucleic Acids Res. 2008;36: 6333-42.

58. Gomez-Cabello D, Jimeno S, Fernandez-Avila MJ, Huertas P. New tools to study DNA double-strand break repair pathway choice. PLoS One. 2013:8:e77206.

59. Sfeir A, Symington LS. Microhomology-mediated end joining: a back-up survival mechanism or dedicated pathway? Trends Biochem Sci. 2015:40:701-14.

60. Dudášová Z, Dudáš A, Chovanec M. Non-homologous end-joining factors of Saccharomyces cerevisiae. FEMS Microbiol Rev. 2004;28:581-601.

61. Daley JM, Palmbos PL, Wu D, Wilson TE. Nonhomologous end joining in yeast. Ann Rev Genet. 2005;39:431-51.

62. Krogh BO, Symington LS. Recombination proteins in yeast. Annu Rev Genet. 2004;38:233-71.

63. Aylon Y, Kupiec M. New insights into the mechanism of homologous recombination in yeast. Mut Res. 2004;566:231-48.

64. Seong C, Sehorn MG, Plate I, Shi I, Song B, Chi P, Mortensen U, Sung P, Krejci L. Molecular anatomy of the recombination mediator function of Saccharomyces cerevisiae Rad52. J Biol Chem. 2008;283:12166-74.

65. Shinohara A, Ogawa H, Ogawa T. Rad51 protein involved in repair and recombination in S. cerevisiae is a RecA-like protein. Cell. 1992;69:457-70.

66. Song B, Sung P. Functional interactions among yeast Rad51 recombinase, Rad52 mediator, and replication protein A in DNA strand exchange. J Biol Chem. 2000;275:15895-904

67. Sugiyama T, Kowalczykowski SC. Rad52 protein associates with replication protein A (RPA)-single-stranded DNA to accelerate Rad51-mediated displacement of RPA and presynaptic complex formation. J Biol Chem. 2002;277:31663-72.

68. Hays SL, Firmenich AA, Berg P. Complex formation in yeast double-strand break repair: participation of Rad51, Rad52, Rad55, and Rad57 proteins. Proc Natl Acad Sci U S A. 1995;92:6925-9.

69. Johnson RD, Symington LS. Functional differences and interactions among the putative RecA homologs Rad51, Rad55, and Rad57. Mol Cell Biol. 1995; 15:4843-50.

70. Sung P. Yeast Rad55 and Rad57 proteins form a heterodimer that functions with replication protein A to promote DNA strand exchange by Rad51 recombinase. Genes Dev. 1997;11:1111-21.

71. Mortensen UH, Bendixen C, Sunjevaric I, Rothstein R. DNA strand annealing is promoted by the yeast Rad52 protein. Proc Natl Acad Sci U S A. 1996;93: 10729-34.

72. Aylon Y, Liefshitz B, Bitan-Banin G, Kupiec M. Molecular dissection of mitotic recombination in the yeast Saccharomyces cerevisiae. Mol Cell Biol. 2003;23: 1403-17.

73. Petukhova G, Stratton S, Sung P. Catalysis of homologous DNA pairing by yeast Rad51 and Rad54 proteins. Nature. 1998;393:91-4.
74. Petukhova G, Sung P, Klein H. Promotion of Rad51-dependent D-loop formation by yeast recombination factor Rdh54/Tid1. Genes Dev. 2000;14:2206-15.

75. Heyer W-D, Li X, Rolfsmeier M, Zhang X-P. Rad54: the Swiss Army knife of homologous recombination? Nucleic Acids Res. 2006;34:4115-25.

76. Raoul Tan TL, Kanaar R, Wyman C. Rad54, a Jack of all trades in homologous recombination. DNA Repair. 2003;2:787-94.

77. Krejci L, Song B, Bussen W, Rothstein R, Mortensen UH, Sung P. Interaction with Rad51 is indispensable for recombination mediator function of Rad52. J Biol Chem. 2002;277:40132-41.

78. Shinohara A, Ogawa T. Stimulation by Rad52 of yeast Rad51-mediated recombination. Nature. 1998;391:404-7.

79. San Filippo J, Sung P, Klein H. Mechanism of eukaryotic homologous recombination. Annu Rev Biochem. 2008;77:229-57.

80. Thorslund T, West SC. BRCA2: a universal recombinase regulator. Oncogene. 2007:26:7720-30.

81. Rijkers T, Van Den Ouweland J, Morolli B, Rolink AG, Baarends WM, Van Sloun PPH, Lohman PHM, Pastink A. Targeted inactivation of mouse RAD52 reduces homologous recombination but not resistance to ionizing radiation. Mol Cell Biol. 1998:18:6423-9.

82. Yamaguchi-Iwai Y, Sonoda E, Buerstedde J-M, Bezzubova O, Morrison C, Takata M, Shinohara A, Takeda S. Homologous recombination, but not DNA repair, is reduced in vertebrate cells deficient in RAD52. Mol Cell Biol. 1998; 18:6430-5.

83. Symington LS. Role of RAD52 epistasis group genes in homologous recombination and double-strand break repair. Microbiol Mol Biol Rev. 2002;66:630-70.

84. Ito-Harashima S, Hartzog PE, Sinha H, McCusker JH. The tRNA-Tyr gene family of Saccharomyces cerevisiae: agents of phenotypic variation and position effects on mutation frequency. Genetics. 2002;161:1395-410.

85. McCusker JH, Clemons KV, Stevens DA, Davis RW. Genetic characterization of pathogenic Saccharomyces cerevisiae isolates. Genetics. 1994;136:1261-9.

86. McCullough MJ, Clemons KV, Farina C, McCusker JH, Stevens DA. Epidemiological investigation of vaginal Saccharomyces cerevisiae isolates by a genotypic method. J Clinic Microbiol. 1998;36:557-62.

87. Glerum DM, Muroff I, Jin C, Tzagoloff A. COX15 codes for a mitochondrial protein essential for the assembly of yeast cytochrome oxidase. J Biol Chem. 1997;272:19088-94.

88. Hawk JD, Stefanovic L, Boyer JC, Petes TD, Farber RA. Variation in efficiency of DNA mismatch repair at different sites in the yeast genome. Proc Natl Acad Sci U S A. 2005;102:8639-43.

89. Lang Gl, Murray AW. Mutation rates across budding yeast chromosome $\mathrm{VI}$ are correlated with replication timing. Genome Biol Evol. 2011;3:799-811.

90. Prakash S, Johnson RE, Prakash L. Eukaryotic Translesion synthesis DNA polymerases: specificity of structure and function. Annu Rev Biochem. 2005;74:317-53.

91. Lehmann AR, Niimi A, Ogi T, Brown S, Sabbioneda S, Wing JF, Kannouche PL, Green CM. Translesion synthesis: Y-family polymerases and the polymerase switch. DNA Repair. 2007;6:891-9.

92. Hoege C, Pfander B, Moldovan GL, Pyrowolakis G, Jentsch S. RAD6dependent DNA repair is linked to modification of PCNA by ubiquitin and SUMO. Nature. 2002;419:135-41.

93. Garg P, Burgers PM. Ubiquitinated proliferating cell nuclear antigen activates translesion DNA polymerases $\eta$ and REV1. Proc Natl Acad Sci U S A. 2005; 102:18361-6.

94. Stelter P, Ulrich HD. Control of spontaneous and damage-induced mutagenesis by SUMO and ubiquitin conjugation. Nature. 2003;425:188-91.

95. Waters LS, Walker GC. The critical mutagenic translesion DNA polymerase Rev1 is highly expressed during G2/M phase rather than S phase. Proc Natl Acad Sci U S A. 2006;103:8971-6.

96. Blastyak A, Pinter L, Unk I, Prakash L, Prakash S, Haracska L. Yeast Rad5 protein required for postreplication repair has a DNA helicase activity specific for replication fork regression. Mol Cell. 2007;28:167-75.

97. Liebman SW, Sherman F. Inhibition of growth by amber suppressors in yeast. Genetics. 1976;82:233-49.

98. Rothstein RJ, Esposito RE, Esposito MS. The effect of ochre suppression on meiosis and ascospore formation in Saccharomyces. Genetics. 1977;85:35-54

99. Singh A. Nonsense suppressors of yeast cause osmotic-sensitive growth Proc Natl Acad Sci U S A. 1977;74:305-9.

100. Namy O, Duchateau-Nguyen G, Rousset JP. Translational readthrough of the PDE2 stop codon modulates CAMP levels in Saccharomyces cerevisiae. Mol Microbiol. 2002;43:641-52. 
101. Stansfield I, Jones KM, Kushnirov W, Dagkesamanskaya AR, Poznyakovski Al, Paushkin SV, Nierras CR, Cox BS, Ter-Avanesyan MD, Tuite MF. The products of the SUP45 (eRF1) and SUP35 genes interact to mediate translation termination in Saccharomyces cerevisiae. EMBO J. 1995;14:4365-73.

102. Cox BS. $\Psi$, a cytoplasmic suppressor of super-suppressor in yeast. Heredity. 1965;20:505-21.

103. Glover JR, Kowal AS, Schirmer EC, Patino MM, Liu J-J, Lindquist S. Selfseeded fibers formed by Sup35, the protein determinant of $\left[\mathrm{PSI}^{+}\right]$, a heritable prion-like factor of S. cerevisiae. Cell. 1997;89:811-9.

104. Wakem LP, Sherman F. Isolation and characterization of omnipotent suppressors in the yeast Saccharomyces cerevisiae. Genetics. 1990;124:515-22.

105. Stansfield I. Akhmaloka, Tuite MF: A mutant allele of the SUP45 (SAL4) gene of Saccharomyces cerevisiae shows temperature-dependent allosuppressor and omnipotent suppressor phenotypes. Curr Genet. 1995;27:417-26.

106. Eaglestone SS, Cox BS, Tuite MF. Translation termination efficiency can be regulated in Saccharomyces cerevisiae by environmental stress through a prion-mediated mechanism. EMBO J. 1999;18:1974-81.

107. True HL, Lindquist SL. A yeast prion provides a mechanism for genetic variation and phenotypic diversity. Nature. 2000;407:477-83.

108. True HL, Berlin I, Lindquist SL. Epigenetic regulation of translation reveals hidden genetic variation to produce complex traits. Nature. 2004;431:184-7.

109. Namy O, Galopier A, Martini C, Matsufuji S, Fabret C, Rousset JP. Epigenetic control of polyamines by the prion $\left[\mathrm{PSI}^{+}\right]$. Nat Cell Biol. 2008;10:1069-75.

110. Tyedmers J, Madariaga ML, Lindquist S. Prion switching in response to environmental stress. PLoS Biol. 2008;6:e294.

111. Saccharomyces Genome Database (SGD). http://www.yeastgenome.org.

112. Raghuraman MK, Winzeler EA, Collingwood D, Hunt S, Wodicka L, Conway A, Lockhart DJ, Davis RW, Brewer BJ, Fangman WL. Replication dynamics of the yeast genome. Science. 2001;294:115-21.

\section{Submit your next manuscript to BioMed Central and we will help you at every step:}

- We accept pre-submission inquiries

- Our selector tool helps you to find the most relevant journal

- We provide round the clock customer support

- Convenient online submission

- Thorough peer review

- Inclusion in PubMed and all major indexing services

- Maximum visibility for your research

Submit your manuscript at www.biomedcentral.com/submit 